\title{
Primary amyloidosis of the bladder mimicking bladder tumor
}

\author{
Ömer Bayrak ${ }^{1}$, Zehra Bozdağ르, Gökhan Urgun ${ }^{1}$, Faruk Yağcl ${ }^{1}$
}

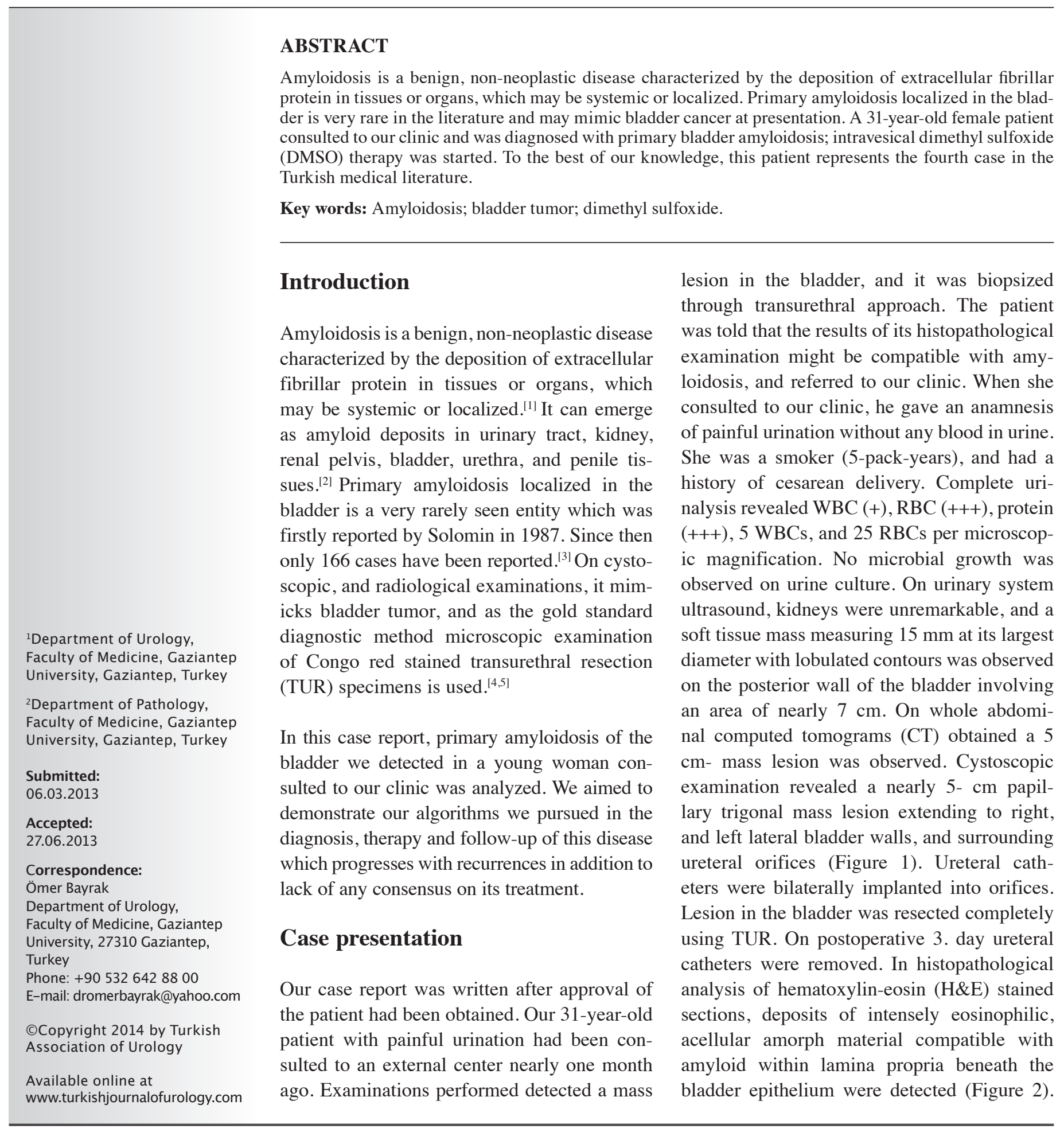




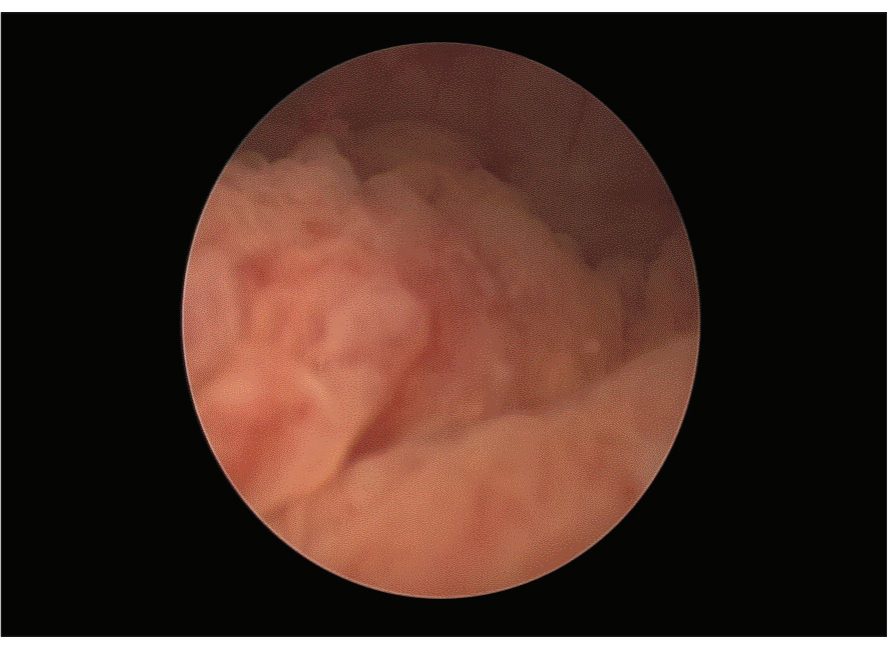

Figure 1. Cystoscopic appearance of the tumor extending to the left lateral wall

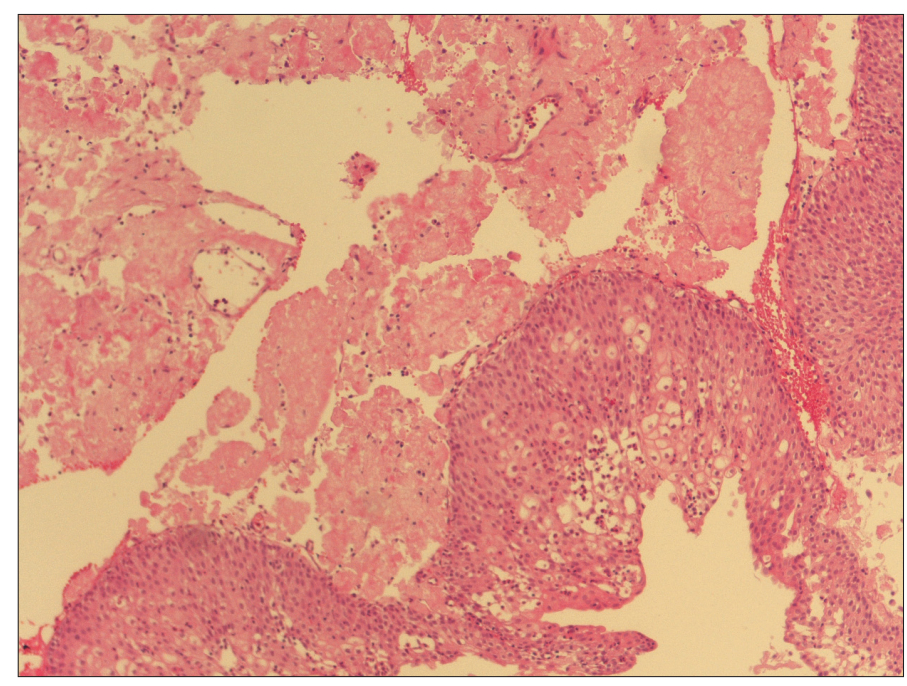

Figure 2. Deposits of eosinophilic, acellular material in the lamina propria beneath vesacal epithelial layer $(H \& E$ x 40)

Histopathological staining with crystal violet, and Congo red indicated presence of amyloid (Figure 3).

Then, the patient was consulted to the Department of Nephrology for systemic amyloidosis. Any mutation was not detected in Familial Mediterranean Fever (FMF) MEFV gene. In serologic tests, levels of complements $\mathrm{C} 3$, and $\mathrm{C} 4$ were within normal limits. In enzyme-linked immunosorbent assay (ELISA) anti DS DNA, in manual IFA (Immunofluorescent assay) C-ANCA, ANA, P-ANCA, and urine micrototal protein test results were within normal limits. Histopathological analysis of colonic, and renal biopsy specimens retrieved was unremarkable.

Intravesical dimethyl sulfoxide (DMSO) therapy, and oral colchicine treatment were planned with the diagnosis of iso-

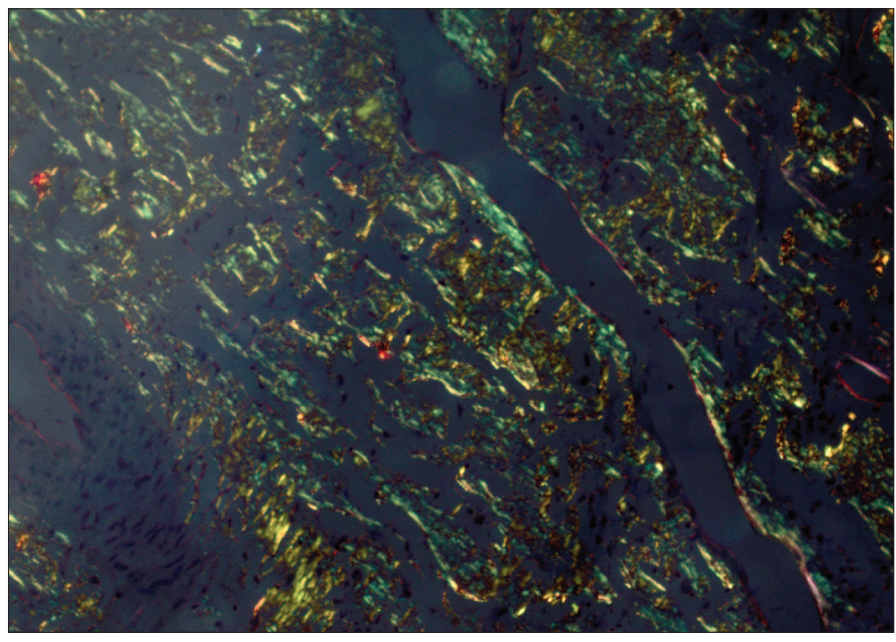

Figure 3. Apple-green bireflectance of amyloid deposits under polarized microscopy

lated vesical amyloidosis. However, when severe complaints of nausea-vomiting emerge, maintenance of treatment with intravesical DMSO was decided upon. During early postoperative follow-ups, irritative voiding problems disappeared, and any pathology was not seen in the first two periodic cystoscopic examinations. However, at postoperative $9^{\text {th }}$ month, her severe urination complaints started again, and on cystoscopic examination, a recurrent tumor nearly $3 \mathrm{~cm}$ in size at the same location of the primary tumor was observed, and resected. Based on available literature data, re-TUR was planned if recurrent tumor was detected following DMSO treatment, and during cystoscopic controls.

\section{Discussion}

Isolated bladder amyloidosis is a very rarely reported disease which courses with painless hematuria, and irritative voiding symptoms, and might mimick bladder tumors ${ }^{[6]}$ Even though a clear algorithm is not available about its treatment, higher recurrence rates can be seen. ${ }^{[3]}$ Wilkinson et al. ${ }^{[6]}$ detected post-TUR primary bladder amyloidosis in a 69-year-old female patient with complaints of painless hematuria dating back to 18 months ago. In this case, successful outcomes were reported with DMSO, and oral colchicine therapy, and cystoscopic follow-ups were recommended.

Patel et al. ${ }^{[3]}$ detected primary bladder amyloidosis in a 38-yearold patient, and applied $2 \mathrm{mg}$ bid oral colchicine, and intravesical DMSO therapies. They didn't encounter any recurrent tumor on cystoscopic examination performed at the end of the first year. However, Tirzman et al. ${ }^{[7]}$ followed up 24 patients with localized bladder amyloidosis, and reported resolution of the disease in $25 \%$, persistence of lesions in $21 \%$, and recurrences in $54 \%$ of the patients. Following three years of disease-free 
period, any episode of recurrence was not observed. In our patient, recurrence observed at 9 . month suggested that the disease can progress with recurrences in its early phase.

The case with the longest follow-up period reported in the literature, had been followed up for 26 years with the indication of chronic primary bladder amyloidosis. During this period,TUR had been applied for 6-fold, and results of all histopathological analyses had been reported as amyloidosis. However his last cystoscopic examination revealed the presence of multiple solid nodular structures resembling yellow-colored adipose tissue localized on membranous urethra, and bladder right wall. PostTUR histopathology report indicated transitional cell carcinoma (TCC) with muscular involvement, and amyloidosis. On CT, right hydroureteonephrosis was detected, and he had undergone radical cystectomy, and ileal loop operation. Cystectomy specimen was reported as TCC with sarcomatoid differentiation, and amyloidosis. Besides histopathological examination of specimens harvested from lower end of the ureter had revealed areas compatible with amyloidosis, and any malignancy was not observed. The authors indicated that amyloidosis does not led to the development of bladder tumor, and during the follow-up period, bladder tumor emerges as an independent disease state. ${ }^{[8]}$

As far as we can get relevant information, in our country, only 3 cases of isolated bladder amyloidosis have been reported. In a case reported by Demir et al. ${ }^{[9]}$ in the year 2000, amyloidosis was detected in a 57-year-old male patient who had undergone TUR with the initial diagnosis of bladder tumor. Since he was lost to follow up, further examinations, and investigations couldn't be performed. Another case of amyloidosis was reported by Çakıroğlu et al. ${ }^{[10]}$ in a 66 -year-old female patient. On ultrasonograms of the patient who presented with painless hematuria, increase in the bladder wall thickness was detected. The patient had undergone TUR, and in histopathological specimens, patchy areas stained positively with Congo red were detected which led to the establishment of the diagnosis of bladder amyloidosis.

In the light of available literature data, post-TUR intravesical DMSA, and oral colchicine therapies are recommended in patients with established primary bladder amyloidosis. [3,7] Though we also planned to use these treatment modalities, we only applied post-TUR intravesical DMSO for the patient who couldn't tolerate colchicine During early postoperative follow-ups, irritative voiding problems disappeared, and any pathology was not seen in the first two periodic cystoscopic examinations. However, at postoperative $9^{\text {th }}$ month, her severe urination complaints started again, and on cystoscopic examination tumor recurrence was observed., Based on available litera- ture data, re-TUR was planned if recurrent tumor was detected following DMSO treatment, and during cystoscopic controls. Treatment to be administered in case of tumor recurrence in the future is not determined, and because of younger age of the patient radical approaches are debatable.

Informed Consent: Written informed consent was obtained from patients who participated in this case.

Peer-review: Externally peer-reviewed.

Author Contributions: Concept -Ö.B.,F.Y.; Design-Ö.B.; Supervision -F.Y.; Funding - Ö.B.; Materials - Ö.B., Z.B.; Data Collection and/or Processing - Ö.B., G.U.; Analysis and/or Interpretation -Ö.B., Z.B.; Literature Review - Ö.B.; Writer - Ö.B.; Critical Review - F.Y.

Conflict of Interest: No conflict of interest was declared by the authors.

Financial Disclosure: The authors declared that this study has received no financial support.

\section{References}

1. Jain M, Kumari N, Chhabra P, Gupta RK. Localized amyloidosis of urinary bladder: A diagnostik dilemma. Indian J Pathol Microbiol 2008;51:247-9.

2. Altwairgi A. Primary amiloidosis of the urinary bladder presenting as painless heamaturia. Int J Health Sci (Qassim) 2011;2:181-6.

3. Patel S, Trivedi A, Dholaria P, Dholakia M, Devra A, Gupta B, et al. Recurrent multifocal primary amyloidosis of urinary bladder. Saudi J Kidney Dis Transpl 2008;19:247-9.

4. Caballero Giné JM, Borrat Font P, Martí Picas L, Ristol Pont J. Amiloidosis vesical: Presentación de dos casos. Actas Urol Esp 2000;24:413-5.

5. Westermark P, Benson MD, Buxbaum JN, Cohen AS, Frangione B, Ikeda S, et al. Amyloid: Toward terminology clarification. Report from the Nomenclature Committee of the International Society of Amyloidosis. Amyloid 2005;12:1-4.

6. Wilkinson M, Fanning DM, Flood H. Primary bladder amyloidosis. BMJ Case Rep DOI: 10.1136/bcr.05.2011.4211.

7. Tirzaman O, Wahner-Roedler DL, Malek RS, Sebo TJ, Li CY, Kyle RA. Primary localized amyloidosis of the urinary bladder: a case series of 31 patients. Mayo Clin Proc 2000;75:1264-8.

8. Gupta P, Hanamshetti S, Kulkarni JN. Primary amyloidosis with high grade transitional cell carcinoma of bladder: a rare case report. J Cancer Res Ther 2012;8:297-9.

9. Demir MA, Türkdoğan P, Özboyacı P. Amyloid tumor of the bladder: A case report. Turkish Journal of Urology 2000;26:381-3.

10. Çakıroğlu B, Ateş L, Gözüküçük R, Güçlü M. Localized primary amyloidosis of the bladder: A case report. Dicle Tip Dergisi 2012;39:422-4. 